\title{
Weldability Assessment of Preheated Ductile Iron Microstructures
}

\author{
Dakwa Yusufu Kwa ${ }^{1}$, Joseph Olatunde Borode ${ }^{2 *}$, Itopa Monday Momoh ${ }^{1}$ \\ ${ }^{1}$ Department of Research and Development, Engineering Materials Development Institute, Akure, Nigeria \\ ${ }^{2}$ Department of Metallurgical and Materials Engineering, Federal University of Technology-Akure, Akure, Nigeria \\ Email: rhodave2011@gmail.com
}

Received August 23, 2012; revised September 27, 2012; accepted October 10, 2012

\begin{abstract}
When joining ductile iron by submerged arc welding technique, a suitable welding speed and current, among other factors, need to be skillfully put in place so as to enhance good welding. This work is based on microstructural examination of preheated ductile iron at various temperatures ranging between $100^{\circ} \mathrm{C}-400^{\circ} \mathrm{C}$. Optical microscope was used for the microstructure analysis. The result shows varied complex microstructures at the fusion zone, un-mixed zone, partially melted zone and at the heat affected zone.
\end{abstract}

Keywords: Submerged Arc Welding; Fusion Zone; Un-Mixed Zone; Heat Affected Zone

\section{Introduction}

The transformation of materials to goods for the satisfaction of human needs is brought into a reality through manufacturing/fabrication processes. Thus, Manufacturing as an indispensable part of production can be considered as a system in which product design at the initial stage is processed and delivered as finished products to the market as the final output for use.

Welding has become a dominant process in manufacturing, without which a large number of products would have to be considerably modified, would be more costly, or could not perform as efficiently if it were not available. It is a process by which two materials are permanently joined together by coalescence, which is induced by a combination of temperature pressure and some other metallurgical conditions. An atomic bonding configuration is formed having a natural election configuration between the two materials by bringing their surfaces together [1]. The ideal weld bond requires a perfectly smooth, flat or matching surface, clean surfaces free from contaminants, materials with no internal impurities, materials that are both single crystals with identical crystallographic structure and orientation. These conditions are impossible to achieve in practice, thus, various welding processes have been developed and preparation designs have been developed to compensate for the imperfection.

In solid state welding processes, contaminated layers are removed by mechanical or chemical action prior to

\footnotetext{
*Corresponding author.
}

welding, or by forcing the metal to flow along the interface so that impurities are squeezed out. In fusion welding, fluxing agents are used to remove contaminants from the pool of molten metal formed during the welding operation. Welding in a vacuum also prevents contamination and promotes the removal of contaminants. Coalescence, therefore, occurs with considerable ease.

A high quality weld therefore requires a source of satisfactory heat and pressure, a means of cleaning and keeping the material free from contamination, and precautions to compensate for, or avoid harmful metallurgical effects.

The development of commercial industries in the late $19^{\text {th }}$ and $20^{\text {th }}$ century, in addition to lessons learnt by catastrophic engineering failures that occurred in that period, brought about a great understanding of the im- portance of welding and weld quality. Fusion welding processes were rapidly developed and improved upon [2]. High amount of carbon, silicon [3] with combination of other elements increases the carbon equivalent of cast iron. High carbon equivalent decreases cast iron's weldability. The objective of improving weldability may be achieved by either preheating, or heat treatment, or both.

Ductile iron is one of the numerous ferrous materials that has its applications both at room temperature and at elevated temperatures. The majority of the reported deterioration in high temperature operating components are microstructural degradation [4,5], hydrogen damage, graphitization, thermal shock, erosion, liquid metal embrittlement, and high temperature corrosion of various types [5]. 
Thus, when joining ductile iron by welding, a suitable welding speed and current [6-8] must be predetermined in order to enhance good welding needed to achieve a set objective(s). This study is, therefore, based on microexamination of structure of fusion and heat affected zones across the weld sections.

\section{Experimental Techniques}

\subsection{Sample Preparation}

A ductile iron of chemical composition 93.52\% Fe, 3.6\% C, $2.5 \% \mathrm{Si}, 0.007 \% \mathrm{P}, 0.3 \% \mathrm{Mn}, 0.01 \% \mathrm{~S}, 0.014 \% \mathrm{Mo}$, $0.05 \% \mathrm{Mg}$ was used in this experiment. After machining to a rectangular bar shape of cross section $10 \mathrm{~mm} \times 23$ $\mathrm{mm}$ and a length of $40 \mathrm{~mm}$ and cut to a $\mathrm{V}$-shape at equidistance point from either edge of the samples following an international standard, the specimen was heat treated to varying temperature ranging between $100^{\circ} \mathrm{C}-400^{\circ} \mathrm{C}$, held for 30 minute in a muffle furnace of accuracy as high as $\pm 2^{\circ} \mathrm{C}$ in order to attain temperature homogeneity in the samples. A minimum of two (2) samples each were treated per treatment for certainty. The samples were subjected to welding at the respective elevated temperatures so as to avoid weld crack that could ensue had it be welded at room temperature. A Submerged Arc Welding (SAW) method was adopted in the joining mechanism using an electrode coded ECI z308. Earlier, the chemical composition of the electrode used has been analyzed as shown in Table 1.

\subsection{Microstructural Investigation}

Microstructural examination was done across the section of the specimen from the fusion zone through the partially melted zone, heat affected zone to the base (heat unaffected zone). Prior to this operation, the welded sample was grinded using a buehler grinder sequentially varying the grinding paper from the coarse (60 micron) to the finest (2400 micron). It was later polished with the aid of a superfine polishing cloth, a diamond polishing

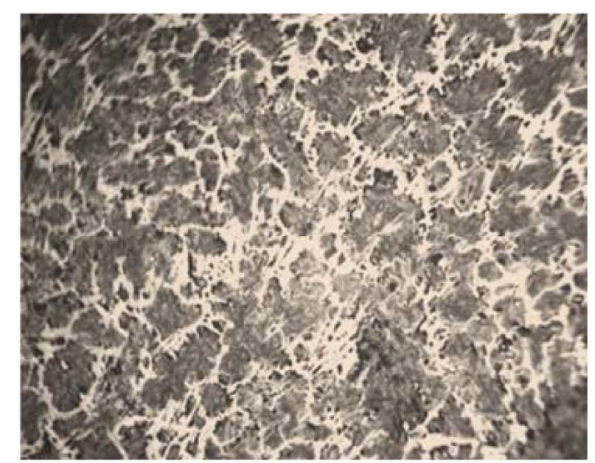

(a)
Table 1. Chemical composition of welding electrode.

\begin{tabular}{cc}
\hline Material & Composition (\%) \\
\hline Carbon & 1.50 \\
Manganese & 2.00 \\
Sulphur & 0.80 \\
Nickel & 0.015 \\
Silicon & 94 \\
Iron & 2 \\
\hline
\end{tabular}

suspension of 3 micron was also used to enhance the mirror-like surface of the material before it was etched with a corresponding etchant-Nital $\left(2 \% \mathrm{HNO}_{3}+98 \%\right.$ Ethanol), captured with an optical microscope of model number 702907 at different magnifications. $\times 100$ magnification was used so as show all necessary sections.

\section{Results and Discussion}

The base metal and the weld regions were microscopically viewed and examined in order to see the microstructural evaluation along the welded trend of preheated ductile iron. Plate 1 shows the microstructure of the base metal. It shows the presence of graphite nodules distributed in a pearlitic matrix and surrounded by ferrites forming boundaries. This corresponds to the findings from literature review [9,10]. Plates 2(a)-(g) also shows the micrographs of the preheated weld joints and its environs. The micrographs shows that there are two (2) major weld sections that includes the fusion zones (FZ), and the heat affected zones (HAZ). Between these two zones is an interface that separates the zones thereby explain distinctly the completely melted region and the unmelted or seemingly melted region. In the FZ, it was observed that the flux in the electrode only act as a catalyst to enhance thorough welding while in itself flows to another region that will be explain in due course.

All microstructures of the HAZ, however, show very different characteristics when compared with the base

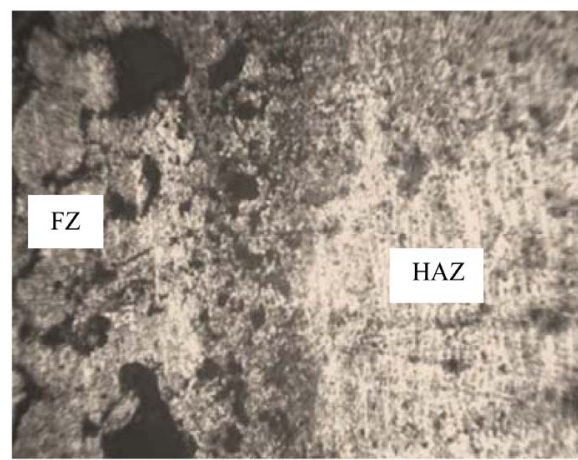

(b)

Plate 1. (a) Microstructure of ductile iron showing graphite nodules in a pearlitic matrix. $\times 200$; (b) fusion line view of specimen welded without preheating. $2 \%$ nital etch, $\times 100$. 


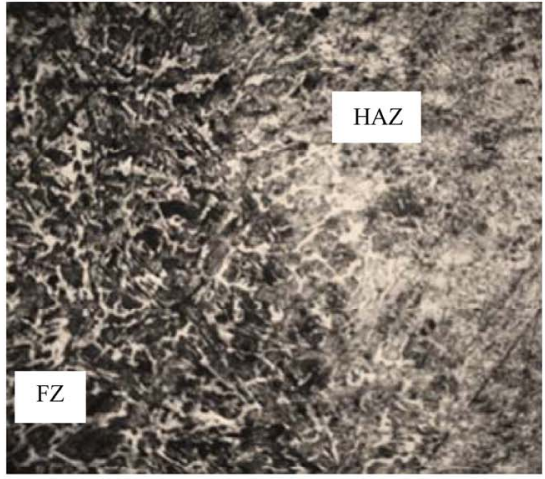

(a)

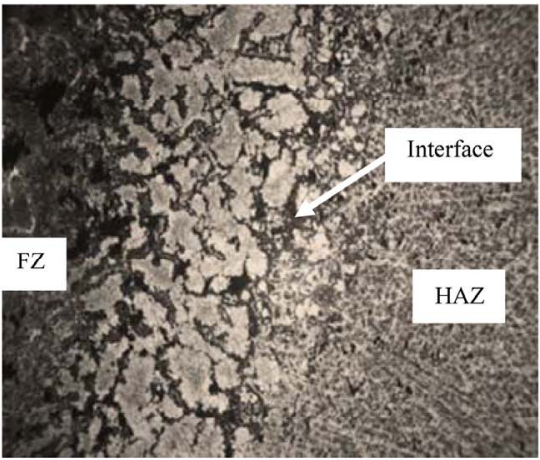

(c)

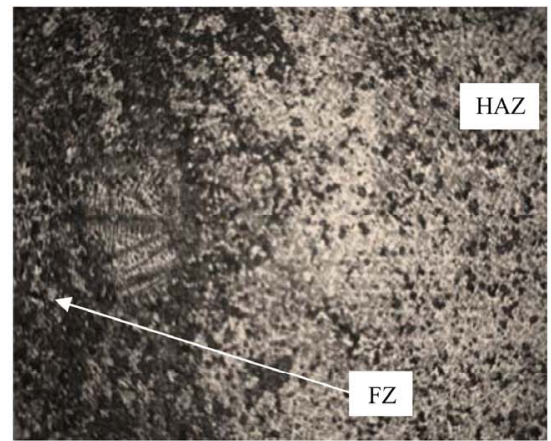

(e)

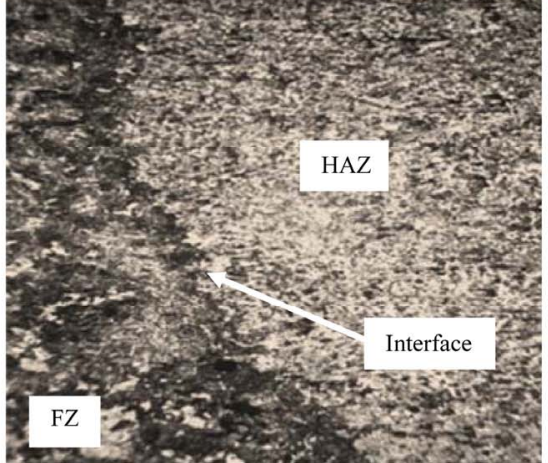

(b)

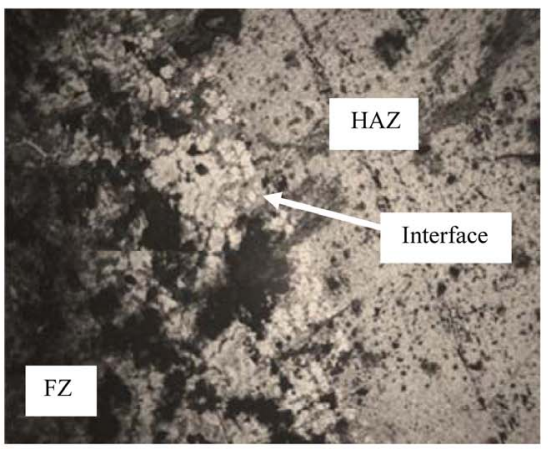

(d)

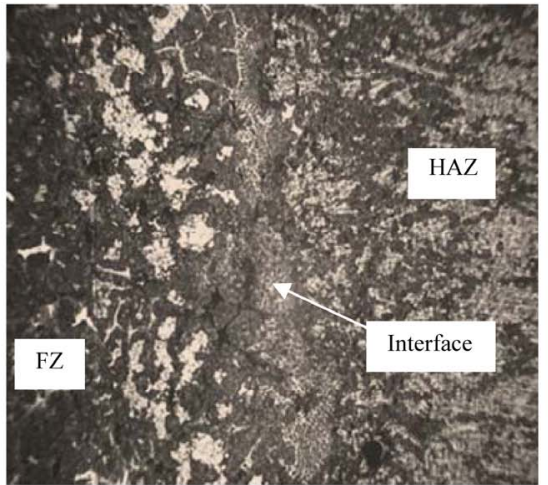

(f)

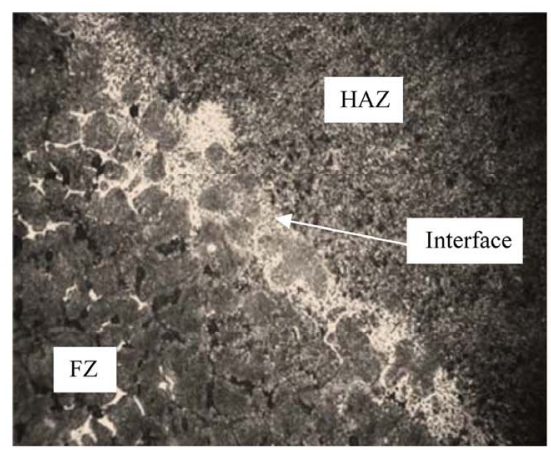

(g)

Plate 2. (a) fusion line view of specimen welded after preheating at $100^{\circ} \mathrm{C} . \times 100$; (b) fusion line view of specimen welded after preheating at $150^{\circ} \mathrm{C} . \times 100$; (c) fusion line view of specimen welded after preheating at $200^{\circ} \mathrm{C} . \times 100$; (d) fusion line view of specimen welded after preheating at $250^{\circ} \mathrm{C} . \times 100$; (e) fusion line view of specimen welded after preheating at $300^{\circ} \mathrm{C} . \times 100$; $(\mathrm{f})$ fusion line view of specimen welded after preheating at $350^{\circ} \mathrm{C} . \times 100 ;(\mathrm{g})$ fusion line view of specimen welded after preheating at $400^{\circ} \mathrm{C} .2 \%$ nital etch, $\times 100$. 
metal. Moving away from the fusion line, the peak temperatures and temperature gradients get lower. Cooling rates are also lower because of the lower temperature gradients. Varied Structures were, thus, formed.

\subsection{Un-Mixed Zone (UMZ)}

The distinct regions in the HAZ can be determined as unmixed zone (UMZ), partially melted zone (PMZ), and true heat affected zone (HAZ). In the HAZ only phase transformations take place. No melting takes place as it is experienced at the UMZ and PMZ. The UMZ region is a completely melted region, but mixing of filler and base metal is not achieved as the filler act as a catalyst-enhancing welding and diffuse out to PMZ. The increased cooling rates enhance the transformation of austenite thus preventing the precipitation of carbon in the liquid to graphite but get trapped in iron carbide which is hard.

\subsection{Partially Melted Zone (PMZ)}

The PMZ forms next to UMZ as a boundary to HAZ. Melting is not total in this zone. The temperature has values between the eutectic and liquids temperature of

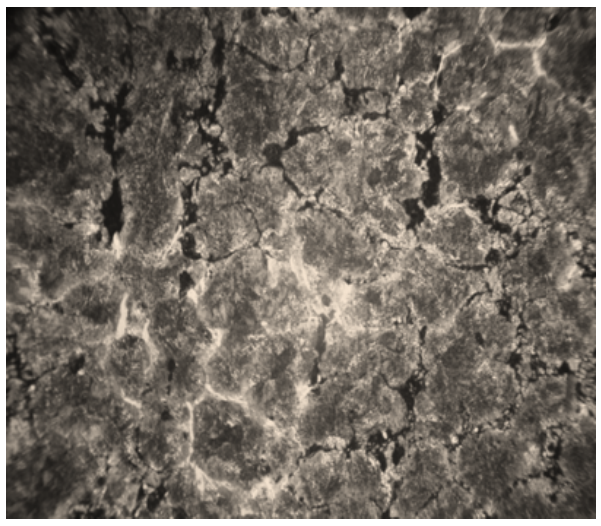

(a)

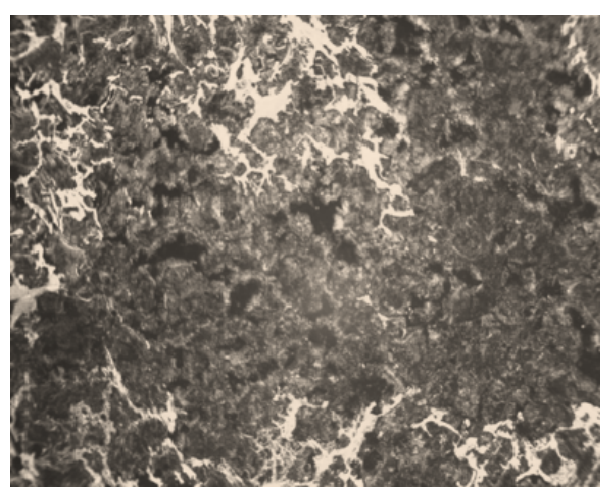

(c) cast iron. Structures formed in this zone are mainly by carbon diffusion out of graphite nodules. At high temperature, the carbon is susceptible to diffusion out of the nodules increasing to concentration of carbon in the surrounding matrix. This continues until melting takes place. High carbon concentration in the surrounding supports eutectic melting, but the high cooling rates cause the melted matrix to transform. Further away from the graphite nodule, melting does not occur and martensite is formed by means of phase transformation.

\subsection{Heat Affected Zone (HAZ)}

No melting takes place at the HAZ. As the distance away from the PMZ is increased, the temperature gradient also gets reduced. The amount of martensite, thus, gets reduced also. The regions close to the PMZ have a martensitic matrix as shown in Plates 3(a)-(d).

\section{Conclusions}

Preheating of ductile iron before welding using a SAW method results in a complex and varied multi-microstructures depending on the preheating temperature and the

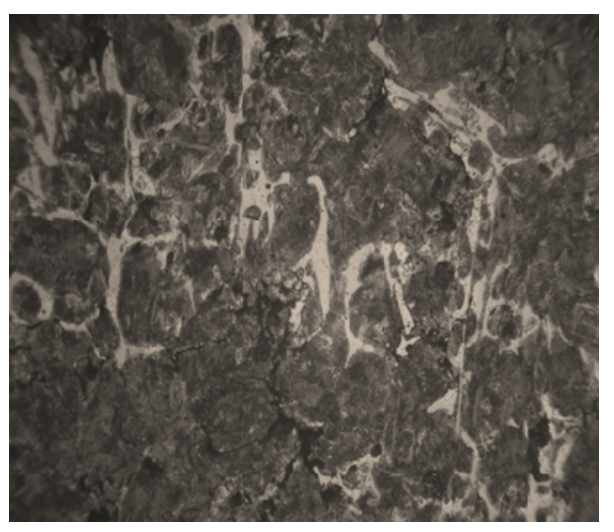

(b)

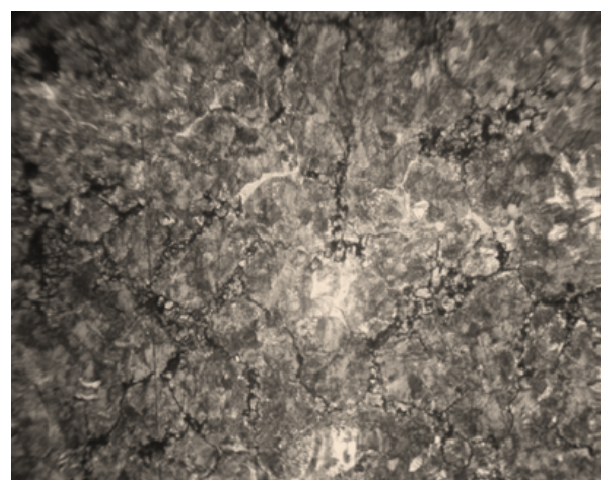

(d)

Plate 3. (a) HAZ of section closest to the base metal in the specimen preheated to $400^{\circ} \mathrm{C}$ showing increased pearlite in the matrix. $\times 400$; (b) $\mathrm{HAZ}$ of section closest to the base metal in the specimen preheated that would otherwise have been martensite. $\times 200$; (c) HAZ of section closest to the base metal in the specimen preheated to $250^{\circ} \mathrm{C} . \times 200$; (d) $\mathrm{HAZ}$ closer to the $\mathrm{PMZ}$ of the specimen welded after preheating at $350^{\circ} \mathrm{C} . \times 200$. 
temperature gradient.

- At $400^{\circ} \mathrm{C}$ before welding, transformation of austenite resulting in the formation of fewer hard structures in the FZ, UMZ, and PMZ, but having a high area fraction of the hard structures (martensite and carbides) at the $\mathrm{HAZ}$ was observed.

- At $300^{\circ} \mathrm{C}$ and $350^{\circ} \mathrm{C}$ before welding produced a higher area fraction of hard structures in the PMZ and fewer hard structures in the $\mathrm{FZ}$ and HAZ.

- At $100^{\circ} \mathrm{C}, 150^{\circ} \mathrm{C}, 200^{\circ} \mathrm{C}$, and $250^{\circ} \mathrm{C}$, the microstructures at the $\mathrm{FZ}$ formed were visually estimated to be lower and equal relative to other zones.

- Preheating of ductile iron, when carried out using SAW method using ECI Z308 electrodes enhances better microstructure that could in turn enhances the mechanical properties.

\section{REFERENCES}

[1] R. W. Messler, "Joining of Materials and Structures from Pragmatic process to Enabling Technology," Butter Worth Heinemann, Burlington, 2004.

[2] R. Blondeau, "Metallurgy and Mechanics of Welding: Processes and Industrial Applications,” Wiley, Hoboken, 2008.

[3] A. V. Adedayo and B. Aremo, "Influence of Mould Heat Storage Capacity on Properties of Grey Iron,” Journal of Minerals \& Materials Characterization \& Engineering, Vol. 10, No. 4, 2011, pp. 387-396.
[4] C. Barbosa, J. L. Nascimento, I. M. V. Caminha and I. C. Abud, "Microstructural Aspects of the Failure Analysis of Nickel Base Superalloys Components," Engineering Failure Analysis, Vol. 12, No. 3, 2005, pp. 348-361. doi:10.1016/j.engfailanal.2004.09.010

[5] A. M. Babakr, A. Al-Ahmari, K. Al-Jumayiah and F. Habiby, "Sigma Phase Formation and Embrittlement of Cast Iron-Chromium-Nickel (Fe-Cr-Ni) Alloys,” Journal of Minerals \& Materials Characterization \& Engineering, Vol. 7, No. 2, 2008, pp. 127-145.

[6] E. M. El-Banna, "Effect of Preheat on Welding of Ductile Cast Iron,” Materials Letters, Vol. 4, No. 1, 1999, pp. 20-26.

[7] W. L. Galvery and F. B. Marlow, "Welding Essentials," Galvery and Marlow Industrial Press, New York, 2007,

[8] H. B. Cary and S. Hetzer, "Modern Welding Technology," Cary and Hetzer Prentice Hall, Upper Saddle River, New Jersey, 2004,

[9] D. M. Viano, N. U. Ahmed and G. O. Schumann, "Influence of Heat Input and Travel Speed on Microstructure and Mechanical Properties of Double Tandem Submerged Arc High Strength Low Alloy Steel Weldments,” Journal of Science and Technology of Welding and Joining, Vol. 5, No. 1, 2000, pp. 26-34. doi:10.1179/136217100322910642

[10] P. Keshav and D. K. Dwivedi, "Microstructure and Tensile Properties of Submerged Arc Welded 1.25Cr-0.5Mo Steel Joints,” Journal of Materials and Manufacturing Processes, Vol. 23, No. 5, 2008, pp. 463-468. doi:10.1080/10426910802103551 